\title{
Relationship between self-care continuation and self-efficacy in patients with secondary lower extremity lymphedema: A questionnaire survey
}

\author{
Risa Fukuda ${ }^{* 1}$, Chiharu Akazawa1, Chitose Arakawa ${ }^{2}$ \\ ${ }^{1}$ Department of Nursing, School of Human Health Science, Graduate School of Medicine, Kyoto University, Kyoto, Japan \\ ${ }^{2}$ Department of Human Nursing, School of Human Nursing, University of Shiga Prefecture, Shiga, Japan
}

Received: July 12, 2015

DOI: $10.5430 /$ jnep.v5n12p57

\author{
Accepted: August 24, 2015 \\ Online Published: September 17, 2015 \\ URL: http://dx.doi.org/10.5430/jnep.v5n12p57
}

\begin{abstract}
Objective: Complex physical therapy (CPT) has recently become the therapeutic focus for managing secondary lymphedema. Although it is advisable to perform CPT every day, only a few of our patients with lymphedema currently maintain this regimen. The aims of our study were to (1) assess the self-care practices that were employed by our patients with secondary lower extremity lymphedema, and to (2) determine the relationship between self-care continuation and self-efficacy in these patients.

Methods: This cross-sectional study was conducted at Kyoto University Hospital's Consultation Room for Women's Mental and Physical Health, and evaluated patients with secondary lower extremity lymphedema. A total of 118 patients were invited to anonymously complete a self-administered questionnaire regarding their demographic information, current self-care habits for manual lymphatic drainage and compression therapy, and self-efficacy rating. We used this data to compile descriptive statistics and compare the differences in the respondents self-efficacy scale scores, according to their continuation of self-care status.

Results: Approximately $64 \%$ of the invited patients returned the questionnaires, and $30 \%$ of these patients reported not continuing self-care, mainly because of the "cumbersome" and "time-consuming" procedures and the belief that self-care "did not result in much improvement". There was no significant difference in the self-efficacy scale scores between the groups that did or did not continue self-care, although the scores tended to be higher in the groups that continued self-care.

Conclusions: These findings indicate that patients with lymphedema should be educated regarding the benefits of self-care, as a large percentage of these patients ultimately discontinued self-care. Therefore, these patients should be informed that only minor apparent changes in lymphedema state are expected, in order to better understand the effects of daily self-care.
\end{abstract}

Key Words: Compression therapy, Cross-sectional study, Lymphedema, Manual lymphatic drainage, Self-care, Self-efficacy

\section{INTRODUCTION}

The annual worldwide number of patients who require surgery because of uterine and breast cancer has recently exhibited annual increases. ${ }^{[1,2]}$ Approximately 25\%-40\% of these patients report swelling in their legs after surgery, and $10 \%-20 \%$ of these patients are clinically diagnosed with lower limb lymphedema. ${ }^{[3,4]}$ Furthermore, $10 \%-65 \%$ of the patients who undergo surgery for breast cancer also report experiencing lymphedema after surgery. ${ }^{[5-7]}$ In Japan, lymphedema develops in $10 \%$ and $25 \%$ of the patients who undergo surgery for uterine and breast cancer, respectively. ${ }^{[8]}$

Previous studies have reported that cancer survivors expe-

*Correspondence: Risa Fukuda; Email: r-fukuda@umin.ac.jp; Address: Shitsukawa, Toon, Ehime 791-0295, Japan. 
rience pain, fatigue, peripheral neuropathy, lymphedema, gastrointestinal complications, sleep disturbance, bladder dysfunction, and menopause. ${ }^{[9]}$ Among these conditions, lymphedema is thought to be specific to patients who survive breast and gynecological cancers. ${ }^{[9,10]}$ Furthermore, the Sociology of Cancer research group surveyed the concerns and burdens of 7,885 Japanese cancer survivors, and reported that swelling (edema) due to secondary lymphedema was the foremost concern of patients who survived uterine cancer. ${ }^{[11]}$

In recent years, the focus of treatment for secondary lymphedema has shifted to complex physical therapy $(\mathrm{CPT}),{ }^{[12-16]}$ which combines appropriate skin care, manual lymphatic drainage (MLD), compression therapy (bandage or elastic stockings; CB) and exercise. Although it is advisable to perform CPT every day, ${ }^{[13,17,18]}$ only a few of our patients with lymphedema maintain this regimen, and many patients ultimately discontinue MLD and CB. Furthermore, these procedures are central components of CPT, and the techniques that are used for these procedures are specialized and time-consuming, which may explain why patients stop using them. Nevertheless, the motivations for discontinuation of MLD and CB have not been reported in previous studies.

Self-efficacy has become an important consideration in several areas of human performance, including health behavior modification, ${ }^{[19]}$ where it describes a sense of personal control over desired changes or a belief that an individual can accomplish a specific behavior. ${ }^{[20]}$ Although previous studies have demonstrated that self-efficacy could be associated with the self-care for chronic disease, ${ }^{[21-24]}$ little is known regarding the relationship between self-care and self-efficacy in patients with lymphedema. Therefore, the present study evaluated the self-care status of patients with secondary lymphedema in their lower extremities, and explored the relationship between self-care continuation and self-efficacy in these patients.

\section{MethodS}

\subsection{Study design and duration}

Data for this cross-sectional study were gathered during January and February 2011.

\subsection{Setting}

This study was conducted at Kyoto University Hospital's Consultation Room for Women's Mental and Physical Health. This national university hospital in Japan has 21 departments, in addition to the Consultation Room, and different specialists provide daily consultations to women with health-related issues. In addition, a nurse who specializes in lymphedema provides weekly consultations and treatment to patients with lymphedema. This nurse provides guidance regarding selfcare, including skin care and exercise, and educates the patients regarding $\mathrm{CB}$ (compression garments or bandaging) and MLD (self-massage) when necessary.

\subsection{Participants and survey methods}

We invited all patients with secondary lymphedema in their lower extremities who visited the Consultation Room for Women's Mental and Physical Health to enroll in this study. Patients were excluded if their native language was not Japanese or if they suffered from dementia. A total of 118 women with secondary lymphedema in their lower extremities were enrolled; each patient was mailed an anonymous self-administered questionnaire, which they were asked to complete and return to the research group via mail.

\subsection{Questionnaire items}

\subsubsection{Demographic variables}

Demographic data included information regarding the year of the patient's surgery, time since the surgery, time of lymphedema onset (years since the surgery), state of the edema, age, and information regarding the person who provided support for self-care at home (e.g., husband, wife, daughter).

\subsubsection{Self-care status}

The self-care practices that we assessed were MLD and CB. The questionnaire included the following items: continuation status for MLD and/or CB after visiting our institution, average number of times per week that MLD and/or CB were performed, the MLD areas (for subjects who continually performed MLD), the technique for performing CB (for subjects who continually performed $\mathrm{CB}$ ), and reasons for discontinuing MLD and/or CB (for subjects who discontinued self-care).

\subsubsection{Self-efficacy}

We used the Japanese version of the generalized self-efficacy scale (SE scale). ${ }^{[25]}$ This scale consists of 23 items, and was established by translating the original SE scale. ${ }^{[26]}$ The scores for the translated SE scale range from 23 to 115, and this scale is known to be reliable (a Cronbach's $\alpha$-coefficient of 0.88). ${ }^{[25]}$ Furthermore, the translated SE scale has been confirmed to be valid using its correlation with the Bem SexRole Inventory and the Center for Epidemiologic Studies Depression Scale. ${ }^{[25]}$

\subsection{Data analysis}

After analyzing the questionnaires, we compiled descriptive statistics, and then grouped and compared the SE scale scores, based on the respondents' continuation status for MLD and $\mathrm{CB}$ (continuing group $v s$. discontinued group). We also compared the scores for 3 subgroups: subgroup 1 continued with 
MLD and CB, subgroup 2 continued with MLD or CB, and subgroup 3 discontinued self-care. Inter-group differences in categorical variables were evaluated using the chi-square test, the Mann-Whitney U test was used for normally distributed continuous variables, and the Kruskal-Wallis test was used for non-normally distributed continuous variables. Differences with a $P$-value of $<.05$ were considered significantly different. SPSS software (version 17.0J for Windows, SPSS Inc., Chicago, IL, USA) was used for all analyses.

\subsection{Ethical considerations}

A letter explaining the purpose of the study and that the participants' privacy and personal information would be protected was included with the questionnaire, and all questionnaires were collected anonymously. The return of a completed questionnaire was considered consent for participation. The study protocol was approved by the institutional review board of the Kyoto University Graduate School of Medicine.

\section{RESULTS}

\subsection{Participant characteristics}

The recovery rate for the questionnaires was $64.4 \%(n=76)$. We excluded questionnaires that were $<50 \%$ complete, and questionnaires that did not have answers regarding the status of self-care and the self-efficacy scale questions. Based on these exclusions, data from 56 women was included in our analysis. Table 1 shows the participant characteristic. The average age of the participants was $58.3 \pm 10.0$ years, the average number of years since their surgery was $8.9 \pm 7.1$ years, and the average onset of lymphedema was $2.5 \pm 3.4$ years after their surgery. Only $17(30.4 \%)$ of the participants reported having a person who helped them perform their self-care routine. No significant differences were observed when we compared the demographic characteristics of the patients who did and did not continue self-care.

Table 1. Participant characteristics

\begin{tabular}{|c|c|c|c|c|c|c|c|c|c|c|c|}
\hline \multirow{2}{*}{ Variable } & & \multirow{2}{*}{\multicolumn{2}{|c|}{ Age (years) }} & \multirow{2}{*}{\multicolumn{2}{|c|}{$\begin{array}{l}\text { Time elapsed since } \\
\text { surgery (years) }\end{array}$}} & \multirow{2}{*}{\multicolumn{2}{|c|}{$\begin{array}{l}\text { Time since the onset of } \\
\text { lymphedema (years) }\end{array}$}} & \multicolumn{4}{|c|}{ Does a person support your self-care? } \\
\hline & & & & & & & & \multicolumn{2}{|l|}{ Yes } & \multicolumn{2}{|l|}{ No } \\
\hline \multirow{5}{*}{ MLD } & \multirow{2}{*}{ Continuing } & $\mathrm{N}$ & 39 & $\mathrm{~N}$ & 39 & $\mathrm{~N}$ & 39 & $\mathrm{~N}$ & 14 & $\mathrm{~N}$ & 25 \\
\hline & & Mean (SD) & 58.7 (9.9) & Mean (SD) & $8.3(6.6)$ & Mean (SD) & $2.5(3.3)$ & $\%$ & 35.9 & $\%$ & 64.1 \\
\hline & \multirow{2}{*}{ Discontinued } & $\mathrm{N}$ & 17 & $\mathrm{~N}$ & 17 & $\mathrm{~N}$ & 16 & $\mathrm{~N}$ & 3 & $\mathrm{~N}$ & 14 \\
\hline & & Mean (SD) & $57.5(10.5)$ & Mean (SD) & $10.2(8.1)$ & Mean (SD) & $2.5(3.8)$ & $\%$ & 17.6 & $\%$ & 82.4 \\
\hline & $P$-value & \multicolumn{2}{|l|}{$.68^{*}$} & \multicolumn{2}{|l|}{$.42 * *$} & \multicolumn{2}{|l|}{$.90^{* *}$} & \multicolumn{2}{|c|}{$.22 * * * *$} & & \\
\hline \multirow{5}{*}{ CB } & \multirow{2}{*}{ Continuing } & $\mathrm{N}$ & 40 & $\mathrm{~N}$ & 40 & $\mathrm{~N}$ & 39 & $\mathrm{~N}$ & 12 & $\mathrm{~N}$ & 28 \\
\hline & & Mean (SD) & $58.6(10.4)$ & Mean (SD) & $9.4(7.8)$ & Mean (SD) & $2.5(3.3)$ & $\%$ & 30.0 & $\%$ & 70.0 \\
\hline & \multirow{2}{*}{ Discontinued } & $\mathrm{N}$ & 16 & $\mathrm{~N}$ & 16 & $\mathrm{~N}$ & 16 & $\mathrm{~N}$ & 5 & $\mathrm{~N}$ & 11 \\
\hline & & Mean (SD) & $57.7(9.2)$ & Mean (SD) & $7.6(4.8)$ & Mean (SD) & $2.5(3.8)$ & $\%$ & 31.2 & $\%$ & 68.8 \\
\hline & $P$-value & \multicolumn{2}{|l|}{$.77^{*}$} & \multicolumn{2}{|l|}{$.79 * *$} & \multicolumn{2}{|l|}{$.70 * *$} & \multicolumn{4}{|c|}{$1.00 * * * * *$} \\
\hline \multirow{7}{*}{ Self-care } & \multirow{2}{*}{$\begin{array}{l}\text { Continuing both } \\
\text { MLD and CB }\end{array}$} & $\mathrm{N}$ & 31 & $\mathrm{~N}$ & 31 & $\mathrm{~N}$ & 31 & $\mathrm{~N}$ & 10 & $\mathrm{~N}$ & 21 \\
\hline & & Mean (SD) & $58.3(10.0)$ & Mean (SD) & $9.2(7.0)$ & Mean (SD) & $2.7(3.5)$ & $\%$ & 32.3 & $\%$ & 67.7 \\
\hline & \multirow{2}{*}{$\begin{array}{l}\text { Continuing either } \\
\text { MLD or CB }\end{array}$} & $\mathrm{N}$ & 17 & $\mathrm{~N}$ & 17 & $\mathrm{~N}$ & 16 & $\mathrm{~N}$ & 6 & $\mathrm{~N}$ & 11 \\
\hline & & Mean (SD) & 59.8 (10.9) & Mean (SD) & $7.7(8.2)$ & Mean (SD) & $1.7(2.1)$ & $\%$ & 35.3 & $\%$ & 64.7 \\
\hline & \multirow{2}{*}{ Discontinued } & $\mathrm{N}$ & 8 & $\mathrm{~N}$ & 8 & $\mathrm{~N}$ & 8 & $\mathrm{~N}$ & 1 & $\mathrm{~N}$ & 7 \\
\hline & & Mean (SD) & $55.3(8.3)$ & Mean (SD) & $10.3(4.8)$ & Mean (SD) & $3.2(5.0)$ & $\%$ & 12.5 & $\%$ & 87.5 \\
\hline & $P$-value & $.44^{* * *}$ & & $.24 * * *$ & & $.81^{* * *}$ & & $.61^{*}$ & & & \\
\hline \multirow{3}{*}{ Total } & $\mathrm{N}$ & 56 & & 56 & & 55 & & 17 & & 39 & \\
\hline & Mean (SD) & $58.3(10.0)$ & & $8.9(7.1)$ & & $2.5(3.4)$ & & & & & \\
\hline & \multicolumn{2}{|l|}{$\%$} & & & & & & \multicolumn{2}{|c|}{30.4} & \multicolumn{2}{|l|}{69.6} \\
\hline
\end{tabular}

\subsection{Self-care continuation}

Our findings regarding self-care continuation were that 39 patients $(69.6 \%)$ reported that they continued to perform MLD, 40 patients $(71.4 \%)$ continued to perform $\mathrm{CB}, 31$ patients (55.4\%) continued to perform both MLD and CB (see Table

Published by Sciedu Press
2). Among the 39 patients who reported continuing MLD, 26 patients $(66.7 \%)$ only performed drainage for some of the sites that are required for effective MLD. More than $80 \%$ of the patients reported performing MLD at the following sites: "the axillary fossa on the same side as the swollen leg", 
"the thigh", "the lower extremities", "shoulder rotation", and "abdominal respiration". However, only 40\%-65\% of the patients reported performing MLD at "the side of the body", "the dorsum of the foot", and "the fingers". Among the patients who reported continuing CB, 6 patients $(15 \%)$ used both bandages and elastic stockings, 33 patients $(82.5 \%)$ used only elastic stockings, and 1 patient $(2.5 \%)$ only used a bandage.

The most commonly reported reasons for discontinuing MLD were that it was "cumbersome" $(\mathrm{n}=10,58.8 \%)$, "did not result in much improvement" ( $n=6,35.3 \%)$, "hands could not reach the lower leg" $(n=6,35.3 \%)$, and "was not possible alone" ( $n=6,35.3 \%)$. The most commonly reported reason for discontinuing CB was that it was "time-consuming" $(\mathrm{n}=4,25.0 \%)$; other reasons included "bandages and elastic stockings are uncomfortable to wear on a hot day" and "bandages and elastic stockings are uncomfortable to wear because they exert strong pressure".

Table 2. Self-care status $(\mathrm{N}=56)$

\begin{tabular}{lll}
\hline Groups & $\mathbf{N}$ & $\mathbf{\%}$ \\
\hline MLD & 39 & 69.6 \\
$\quad$ Continuing & 17 & 30.4 \\
$\quad$ Discontinued & & \\
CB & 40 & 71.4 \\
$\quad$ Continuing & 16 & 28.6 \\
$\quad$ Discontinued & & \\
Self-care & 31 & 55.4 \\
Continuing both MLD and CB & 17 & 30.4 \\
Continuing either MLD or CB & 8 & 14.3 \\
$\quad$ Discontinued & & \\
\hline
\end{tabular}

Note. MLD: manual lymphatic drainage; CB: compression therapy

\subsection{The relationship between SE scale scores and self- care continuation}

The mean SE scale score was $78.0 \pm 12.7$. There was no difference in the SE scale scores when we compared the groups that did or did not continue MLD or CB $(P=.23$ and $P=.63$, respectively). In addition, no difference was observed when we compared the 3 subgroups for self-care continuation $(P=$ .56) (see Table 3). Nevertheless, the SE scale scores for the groups that continued MLD and/or CB tended to be higher than those for the groups that discontinued self-care.

\section{Discussion}

\subsection{Self-care status}

Our results revealed that approximately $30 \%$ of the patients who returned our questionnaires reported discontinuing MLD or CB self-care. In addition, only approximately half of the patients who reported continuing MLD also reported completing the entire lymphatic drainage routine. Furthermore, numerous patients reported that they did not perform MLD "on the side of the body", despite this being an important lymphatic drainage site. Moreover, our findings highlighted that commonly reported reasons for discontinuing self-care were that the patients found it to be "cumbersome" and "timeconsuming".

In cases of secondary lymphedema in the lower extremities, MLD should be performed on the visibly swollen leg, as well as on the remaining areas of the body, beginning at the supraclavicular area on the affected side, then moving towards the corresponding axillary fossa, and proceeding to the thigh on the same side of the body. ${ }^{[17]}$ Therefore, it takes 30-40 min to carefully and slowly perform MLD. In addition, patients must learn to tie several bandages (5-6) for $\mathrm{CB}$, and several patients reported discontinuing $\mathrm{CB}$ because it was time consuming. Furthermore, elastic stockings were considered difficult to wear, because of the pressure that they exert on the limbs. Moreover, self-care must be performed daily to be effective, ${ }^{[17,18]}$ rather than every other day or two, because gravity causes blood circulation to stagnate in the lower extremities during the daytime. Therefore, we presume that all of these factors contributed to our patients reporting that MLD and CB were cumbersome and time-consuming.

Interestingly, our participants did not report experiencing the beneficial effects of self-care. This lack of a perceived benefit may be related to the fact that a comparison of the limbs before and after lymphedema treatment is needed to observe the effects of self-care. However, patients typically compare the condition of their lower limbs after self-care with the state of their limbs before the onset of lymphedema. In addition, the beneficial effects of self-care are not immediately visible, and improvements in lymphedema are typically assessed by measuring lower limb circumference, with changes of several millimeters being within the expected measurement error range. ${ }^{[27]}$ Therefore, it is difficult for patients to visualize the changes, which may explain the lack of perceived benefits for self-care.

\subsection{The relationship between SE scale scores and self- care continuation}

Although there were no differences in the SE scale scores for the groups that did and did not continue self-care, the SE scale scores tended to be higher in the groups that continued self-care. Thus, these findings suggest that self-efficacy might be associated with self-care continuation. In studies of chronic disease, improvements in self-efficacy were associated with improvements in exercise, eating behaviors, and physical activity; ${ }^{[28-30]}$ all of these changes can be con- 
sidered self-care. Furthermore, the use of blood glucose self-monitoring devices motivates diabetes patients to continue practicing self-care. ${ }^{[31]}$ Therefore, it may be possible to improve self-care continuation in patients with lymphedema if the patients are provided with measuring instruments to monitor their progress, which may also improve their sense of self-efficacy. Thus, developing devices that visually indicate the effects of self-care may motivate patients to continue self-care therapy.

Table 3. Comparing self-efficacy scale scores according to self-care continuation status

\begin{tabular}{|c|c|c|c|c|}
\hline Groups & $\mathbf{N}$ & Mean \pm SD & Median (range) & $P$-value \\
\hline \multicolumn{5}{|l|}{ MLD $^{*}$} \\
\hline Continuing & 39 & $79.1 \pm 13.0$ & $78.0(54-111)$ & \multirow{2}{*}{.23} \\
\hline Discontinued & 17 & $75.6 \pm 12.1$ & $74.0(62-115)$ & \\
\hline \multicolumn{5}{|l|}{$\mathbf{C B}^{*}$} \\
\hline Continuing & 40 & $78.8 \pm 14.5$ & $78.0(54-115)$ & \multirow{2}{*}{.63} \\
\hline Discontinued & 16 & $76.2 \pm 6.7$ & $77.0(65-87)$ & \\
\hline \multicolumn{5}{|l|}{ Self-care $^{* *}$} \\
\hline Continuing both MLD and CB & 31 & $79.4 \pm 14.2$ & $79.0(54-111)$ & \multirow{3}{*}{.56} \\
\hline Continuing either MLD or CB & 17 & $77.3 \pm 12.4$ & $76.0(62-115)$ & \\
\hline Discontinued & 8 & $74.4 \pm 5.9$ & $76.0(65-81)$ & \\
\hline
\end{tabular}

Note. MLD: manual lymphatic drainage; CB: compression therapy; SD: standard deviation; * Mann-Whitney U test; ** Kruskal-Wallis test

\subsection{Limitations}

This study has several limitations that should be considered. First, data were only collected from patients who received treatment at a single hospital, and the sample size was small. Therefore, our findings may not accurately reflect the perceptions of all patients with secondary lymphedema in the lower extremities. Second, given the cross-sectional design, we cannot determine whether the relationship between selfefficacy and self-care were causal. Third, the use of a selfadministered questionnaire may have introduced selection bias in the patients that we analyzed, and reporting bias in the patients' responses.

Nevertheless, we believe that our findings will be useful for understanding the self-care status of patients with secondary lymphedema in their lower extremities, as little studies have investigated the self-care status and self-efficacy of these patients. Therefore, to confirm our findings, future longitudinal studies should evaluate self-efficacy expectations regarding the benefits of self-care, and should sample patients from various hospitals in broader areas, in order to provide more generalizable data.

\section{Conclusions}

Our findings revealed that $30 \%$ of patients with secondary lymphedema in their lower extremities reported discontinuing self-care (MLD or CB). The reported reasons for discontinuing self-care were the time-consuming and cumbersome nature of the procedures, and the absence of perceived benefits. However, the SE scale scores for the groups that continued MLD and/or CB tended to be higher than those for the groups that discontinued the therapy. Thus, we believe that patients with lymphedema should be educated regarding the benefits of self-care. Moreover, the small changes in lymphedema state should be explained to help patients better understand the effects of daily self-care.

\section{ACKNOWLEDGEMENTS}

We thank the participants of this study. This study was supported by JSPS KAKENHI Grant Number 21659509.

\section{CONFLiCTS OF INTEREST Disclosure}

The authors declare that there is no conflict of interest.

\section{REFERENCES}

[1] Duncan ME, Seagroatt V, Goldacre MJ. Cancer of the body of the uterus: trends in mortality and incidence in England, 19852008. BJOG. 2012 Feb; 119(3): 333-9. PMid:22082282 http: //dx.doi.org/10.1111/j.1471-0528.2011.03201.x

[2] Forouzanfar MH, Foreman KJ, Delossantos AM, et al. Breast and cervical cancer in 187 countries between 1980 and 2010: a systematic analysis. Lancet. 2011 Oct; 378(9801): 1461-84. http: 
//dx.doi.org/10.1016/S0140-6736(11)61351-2

[3] Beesley V, Janda M, Eakin E, et al. Lymphedema after gynecological cancer treatment: prevalence, correlates, and supportive care needs. Cancer. 2007 Jun; 109(12): 2607-14. PMid:17474128 http://dx.doi.org/10.1002/cncr. 22684

[4] Ryan M, Stainton MC, Slaytor EK, et al. Aetiology and prevalence of lower limb lymphedema following treatment for gynaecological cancer. Aust N Z J Obstet Gynaecol. 2003 Apr; 43(2): 148-51. PMid:14712972 http://dx.doi.org/10.1046/j.000 4-8666.2003.00040.x

[5] Disipio T, Rye S, Newman B, et al. Incidence of unilateral arm lymphedema after breast cancer: a systematic review and meta-analysis. Lancet Oncol. 2013 May; 14(6): 500-15. http://dx.doi .org/10. 1016/S1470-2045 (13) 70076-7

[6] Erickson VS, Pearson ML, Ganz PA, et al. Arm edema in breast cancer patients. J Natl Cancer Inst. 2001 Jan; 93(2): 96-111. PMid:11208879 http://dx.doi.org/10.1093/jnci/93.2.96

[7] Shah C, Vicini FA. Breast cancer-related arm lymphedema: incidence rates, diagnostic techniques, optimal management and risk reduction strategies. Int J Radiat Oncol Biol Phys. 2011 Nov; 81(4): 907-14. PMid:21945108

[8] Tsukamoto Y, Endo T, Baba S. Actual Situation and Trend of Study on Lymphedema in Carcinoma. Annual Rport of University of Shizuoka, Shizuoka College. 2005; 19: 1-12. [in Japanese]

[9] Brearley SG, Stamataki Z, Addington-Hall J, et al. The physical and practical problems experienced by cancer survivors: a rapid review and synthesis of the literature. Eur J Oncol Nurs. $2011 \mathrm{Jul} ; 15(3)$ : 204-12. PMid:21489873 http://dx.doi.org/10.1016/j.ejon. 2011.02 .005

[10] Lockwood-Rayermann S. Survivorship issues in ovarian cancer: a review. Oncol Nurs Forum. 2006 May; 33(3): 553-62. PMid:16676012 http://dx.doi.org/10.1188/06.0NF.553-562

[11] Joint Study Group on the Sociology of Cancer. The views of 7,885 people who faced up to cancer: Towards the creation of a database of patients' anxieties. A report on research into the anxieties and burdens of cancer sufferers [Internet]. Shizuoka: Shizuoka Cancer Center. 2004 Jun. 56 p. Available from: http: //cancerqa.scchr .jp/pdf/taiken_koe_eng.pdf

[12] Cheville AL, McGarvey CL, Petrek JA, et al. Lymphedema management. Semin Radiat Oncol. 2003 Jul; 13(3): 290-301. http: //dx.doi.org/10.1016/S1053-4296(03)00035-3

[13] Davis S. Lymphedema following breast cancer treatment. Radiol Technol. 1998 Sep-Oct; 70(1): 42-56. PMid:9779509

[14] International Society of Lymphology. The diagnosis and treatment of peripheral lymphedema. Consensus document of the International Society of Lymphology. Lymphology. 2003 Jun; 36(2): 84-91. PMid:12926833

[15] Sato K, Ogawa Y. Treatment and Care of Lymphedema. Tokyo: Igaku Shoin; 2005.

[16] Twycross R, Jenns K, Todd J. Lymphedema. Translated by Kiba S, Maruguchi M and Shima Y. Tokyo: Chuohoki Publishing Co., Ltd.; 2003.

[17] Lymphedema Framework. Best Practice for the Management of Lymphedema. International Consensus. London: MEP Ltd.; 2006.

[18] Mayrovitz HN. The standard of care for lymphedema: current concepts and physiological considerations. Lymphat Res Biol. 2009;
7(2): 101-8. PMid:19522678 http://dx.doi.org/10.1089/lrb .2009 .0006

[19] Bandura A. Self-efficacy: The exercise of control. New York: Worth Publishers; 1997.

[20] Bandura A. Self-efficacy: toward a unifying theory of behavioral change. Psychol Rev. 1977 Mar; 84(2): 191-215. PMid:847061 http://dx.doi.org/10.1037/0033-295X.84.2.191

[21] Al-Khawaldeh OA, Al-Hassan MA, Froelicher ES. Self-efficacy, self-management, and glycemic control in adults with type 2 diabetes mellitus. J Diabetes Complications. 2012 Jan-Feb; 26(1): 106. PMid:22226484 http://dx.doi.org/10.1016/j.jdiacomp. 2011.11 .002

[22] Warren-Findlow J, Seymour RB, Brunner Huber LR. The association between self-efficacy and hypertension self-care activities among African American adults. J Community Health. 2012 Feb; 37(1): 15-24. PMid:21547409 http://dx.doi.org/10.1007/s 10900-011-9410-6

[23] Wu SF, Huang YC, Lee MC, et al. Self-efficacy, self-care behavior, anxiety, and depression in Taiwanese with type 2 diabetes: A cross-sectional survey. Nurs Health Sci. 2013. PMid:23301516 http://dx.doi.org/10.1111/nhs.12022

[24] Yoo H, Kim CJ, Jang Y, et al. Self-efficacy associated with self-management behaviours and health status of South Koreans with chronic diseases. Int J Nurs Pract. 2011 Dec; 17(6): 599606. PMid:22103826 http://dx.doi.org/10.1111/j.1440-1 72X.2011.01970.x

[25] Narita K, Shimonaka Y, Nakazato K, et al. A Japanese version of the generalized self-efficacy scale-Scale utility from the life-span perspective. Japanese Journal of Educational Pschology. 1995; 43: 306-14. [in Japanese] http://dx. doi .org/10.5926/jjep1953. 43.3_306

[26] Sherer M, Maddux JE, Mercandante B. The self-efficacy scale: Construction and validation. Psychol Rep. 1982 Oct; 51: 663-71. http://dx.doi.org/10.2466/pr0.1982.51.2.663

[27] Chen YW, Tsai HJ, Hung HC, et al. Reliability study of measurements for lymphedema in breast cancer patients. Am J Phys Med Rehabil. 2008 Jan; 87(1): 33-8. PMid:17993983 http://dx.doi.org/10.1097/PHM.0b013e31815b6199

[28] Idowu O, Adeniyi A, Atijosan O, et al. Physical inactivity is associated with low self efficacy and social support among patients with hypertension in Nigeria. Chronic Illn. 2013 Jun; 9(2): 15664. PMid:23175759 http://dx.doi.org/10.1177/174239531 2468012

[29] Richman RM, Loughnan GT, Droulers AM, et al. Self-efficacy in relation to eating behaviour among obese and non-obese women. Int J Obes Relat Metab Disord. 2001 Jun; 25(6): 907-13. PMid:11439307 http://dx.doi.org/10.1038/sj.ijo.0801606

[30] Sol BG, van der Graaf Y, van Petersen R, et al. The effect of selfefficacy on cardiovascular lifestyle. Eur J Cardiovasc Nurs. 2011 Sep; 10(3): 180-6. PMid:20674503 http://dx.doi.org/10.1016/j .ejcnurse.2010.06.005

[31] McIntosh B, Yu C, Lal A, et al. Efficacy of self-monitoring of blood glucose in patients with type 2 diabetes mellitus managed without insulin: a systematic review and meta-analysis. Open Med. 2010; 4(2): e102-13. 